\title{
Trophic ecology of bullet tuna Auxis rochei larvae and ontogeny of feeding-related organs
}

\author{
Elvira Morote ${ }^{1, *}$, M. Pilar Olivar ${ }^{1}$, Patricia M. Pankhurst ${ }^{2}$, Fernando Villate ${ }^{3}$, \\ Ibon Uriarte ${ }^{3}$
}

\author{
${ }^{1}$ Instituto de Ciencias del Mar (CSIC), Paseo Marítimo de la Barceloneta 37-49, 08003 Barcelona, Spain \\ ${ }^{2}$ School of Marine and Tropical Biology, James Cook University, Townsville, Queensland 4811, Australia \\ ${ }^{3}$ Departamento de Biología Vegetal y Ecología, Universidad del País Vasco, Campus de Leioa, Barrio Sarriena s/n, \\ 48940 Leioa, Spain
}

\begin{abstract}
The bullet tuna Auxis rochei, Risso 1810, is a small tuna widely distributed in tropical and temperate seas. The present study reports on the first attempt to jointly monitor diet and food selection in larvae of this species and to assess the influence of the ontogenetic development of feeding-related organs on the diet. A. rochei larvae from 2 to $7 \mathrm{~mm}$ long are diurnal feeders and highly active predators, with high values of feeding incidence, gut fullness and number of ingested prey items. The rate of change in prey item size in relation to larval size was higher than in other species. Only small, non-motile prey items are eaten at the onset of feeding. Rapid mouth development and the early appearance of teeth allow larvae from 3 to $5 \mathrm{~mm}$ long to ingest a wide range of prey. However, niche breadth decreases at $5 \mathrm{~mm}$, when larvae avoid small prey items in favour of larger ones with a higher carbon content. Chesson's selectivity index indicated that small larvae (from 2 to $3 \mathrm{~mm}$ long) selected a variety of small prey items, mainly copepod nauplii. Larvae measuring 3 to $5 \mathrm{~mm}$ selectively ate cladocerans and appendicularians, and larvae with lengths $\geq 5 \mathrm{~mm}$ preferred appendicularians and fish larvae. Precocious body development (mouth, teeth, and onset of stomach and caudal fin development) and improved visual acuity (larger lens diameter and angular cone density) are factors that contribute to the feeding success of larvae of this species.
\end{abstract}

KEY WORDS: Bullet tuna larvae · Feeding ecology · Prey selection · Ontogeny · Vision · NW Mediterranean

Resale or republication not permitted without written consent of the publisher

\section{INTRODUCTION}

The bullet tuna Auxis rochei, Risso 1810, is a commercially important scombrid widely distributed in tropical and subtropical waters around the world. In the NW Mediterranean Sea, the spawning period runs from June to September, with peak larval abundance when water temperature reaches the yearly maximum (Sabatés \& Recasens 2001).

Scombrid larvae have some of the highest growth rates of any marine fish larvae; hence, their food requirements are high (Hunter 1981). Feeding success is a very important factor affecting survival of the early larval stages and thus subsequent recruitment strength. There is evidence that tuna larvae have high mortality levels, mainly as a consequence of starvation (Margulies 1993). More particularly, Auxis spp. larvae have been observed to be prone to starvation on account of their high metabolic rate and fast growth rate (Tanaka et al. 1996 and references therein). Knowledge of the trophic ecology of Auxis rochei larvae is essential to understanding growth and survival of these stages.

Although there have been many studies dealing with larval feeding in scombrids, only a few have actually addressed selection as it relates to prey availability in the sea. Studies on the trophic ecology of Scomber spp. and Scomberomorus spp. are relatively common (e.g. 
Conway et al. 1999), and larval feeding has been assessed for most tuna species (Uotani et al. 1981, Young \& Davis 1990, Catalán et al. 2007). However, studies on the feeding habits of Auxis spp. larvae are limited to work by Uotani et al. (1981), who described the diet composition and prey selection of Auxis spp. in the SE Indian Ocean, and Sánchez-Velasco et al. (1999), who examined the diet composition of Auxis sp. in the Gulf of California.

Fish larvae employ different feeding strategies depending on the area and season of spawning and larval hatching, and these strategies are related to both prey availability and larval development. Prey size is one of the most important factors in prey selection; however, prey availability, prey colour, swimming behaviour and innate predator preferences can strongly affect larval selection (Hunter 1981, Govoni et al. 1986). Digestive system and sensory organ development go hand in hand with changes in larval behaviour that have major implications for feeding and predator avoidance (Hubbs \& Blaxter 1986).

The object of the present study was to provide an overview of the larval feeding ecology of Auxis rochei by analysing diel feeding patterns, feeding incidence (FI), diet composition and selection, ontogenetic diet shift, and predator-prey relationships and to elucidate to what extent this species' larval trophic ecology depends on the ontogenetic development of organs related to feeding and foraging.

\section{MATERIALS AND METHODS}

Field collection of larvae and zooplankton. The study area was located in the NW Mediterranean Sea. The survey was carried out from 16 to 22 June 2005, during the spawning period of Auxis rochei. Larvae were sampled from the inshore region $(50 \mathrm{~m})$ to the offshore region (ca. $600 \mathrm{~m}$ ) by means of oblique Bongo hauls (mesh size of $0.3 \mathrm{~mm}$ ) from a depth of $200 \mathrm{~m}$, or just above the bottom, to the surface. The volume of water filtered by the net was estimated using a flowmeter. The vertical larval distribution was obtained based on 8 stratified hauls (at $10 \mathrm{~m}$ intervals) using a Longhurst Hardy Plankton Recorder. In addition, vertical microplankton and mesoplankton hauls were carried out using a Calvet net fitted with 53 and $200 \mu \mathrm{m}$ mesh. To remove mesoplanktonic organisms from the $>53 \mu \mathrm{m}$ samples, these catches were later filtered through a $200 \mu \mathrm{m}$ mesh. Samples were preserved in $5 \%$ buffered formalin. Larvae for histological examination were fixed in $10 \%$ formalin in $0.1 \mathrm{M}$ phosphate buffer.

Laboratory analyses. A total of 207 intact specimens of Auxis rochei larvae ranging from 2.0 to $6.7 \mathrm{~mm}$ in length were randomly selected from the samples for gut content analysis. In samples of fewer than 10 larvae, all individuals were dissected; in larger samples, a random subsample from 10 to 12 larvae was taken. Before dissection, the following measurements were recorded: standard length (SL); eye diameter (ED); lower jaw length (LJL), measured from the tip to the junction with the maxilla; upper jaw length (UJL), measured from the tip of the snout to the posterior end of the maxilla; and mouth width (MW), measured ventrally as the widest distance between the posterior edge of the maxillae. Dentary and maxillary teeth during the course of development were also studied.

The entire gut from each specimen was removed intact using a fine needle, placed in a drop of $50 \%$ glycerine-distilled water on a glass slide, and prey organisms were teased out for identification, enumeration, and measurement. Identification of food particles in the gut was effected to the lowest taxon possible. Maximum body width and body length of each prey item were measured to the nearest $0.0025 \mathrm{~mm}$ along the maximum cross section under a microscope equipped with an ocular micrometer. The measurements for non-crustacean prey items without exoskeletons were probably smaller than the actual size of live prey because they were partially digested and shapeless in the gut.

Prey availability was determined at 18 selected stations where the Auxis rochei larvae analysed were most abundant. Identified individuals were grouped by the usual coarse planktonic categories, by developmental stage (e.g. copepod eggs, nauplii, and postnauplii), or by specific criteria (e.g. Evadne spp. in cladocerans), using the prey categories chosen for diet analysis. The abundance of each planktonic category was calculated as ind. $\mathrm{m}^{-3}$ for the microplanktonic and mesoplanktonic fractions, and both values were added together to obtain the total prey abundance used to estimate the selectivity index.

Larvae used for histological examination were embedded in glycol methacrylate resin, serially sectioned $(2 \mu \mathrm{m})$ and stained (polychrome stain). Serial transverse sections of the heads of preflexion $(n=4$, $\mathrm{SL}=2.6$ to $3.8 \mathrm{~mm})$, early flexion $(\mathrm{n}=3, \mathrm{SL}=4$ to $5 \mathrm{~mm})$ and late flexion ( $\mathrm{n}=8, \mathrm{SL}=6$ to $7 \mathrm{~mm}$ ) larvae were used to examine changes in visual morphology. In addition, flexion stage larvae ( $\mathrm{n}=4, \mathrm{SL}=4.9$ to $6 \mathrm{~mm}$ ) were serially sectioned (providing tangential sections of the photoreceptors) in order to investigate the arrangement and type of cone photoreceptors in the outer nuclear layer of the retina. The gross morphology of the digestive tract in preflexion and flexion stage larvae was evaluated in whole fixed specimens. Histological evaluation of the digestive tract was performed in late flexion larvae $(\mathrm{n}=3, \mathrm{SL}=6.4$ to $7 \mathrm{~mm})$. 
Dorso-ventral eye and lens diameters were measured in largest diameter serial transverse sections in the central retina. Retinal cell counts (cone and rod photoreceptors) and cone outer segment lengths (measured from the sclerad limit of the pigmented retinal epithelium to the outer limiting membrane of the outer nuclear [photoreceptor nuclei] layer) were quantified in 1 eye from each larva using transverse histological sections with the largest lens diameter in the central retina away from the embryonic fissure and insertion point of the optic nerve. Cone cell density was determined by counting cone ellipsoids. Double cone ellipsoids could not be reliably differentiated from those of single cones in the transverse sections, with the result that single and double cones were counted as single elements. However, the presence of single and double cone photoreceptors was confirmed in tangential sections in which single and double cones could be resolved. Rod photoreceptors were determined by counting their nuclei (more densely stained and smaller than cone nuclei, with different shape and position). Retinal cell densities were determined along a single linear transect of the retina $50 \mu \mathrm{m}$ in length in each of the dorsal, middle, and ventral retina. Small eye size and curvature of the retina limited the retinal area available for cell density determination, particularly in the smallest larvae (Browman et al. 1990, Pankhurst et al. 1993). Three measurements of cone photoreceptor outer segment length were made in each retinal region. Angular cell densities to correct for the curvature of the eye were calculated for cones and rods as cited in Poling \& Fuiman (1997).

Data analysis. Differences in the data were analysed using ANOVAs and nonparametric tests (Mann-Whitney or Kruskal-Wallis) with SPSS software package for windows (SPSS 2005). FI was calculated as the percentage of larvae with gut contents out of the total number of larvae examined in the daytime and at night. The gut fullness index was estimated on a scale of 0 to 4 (0 = empty; $1=25 \%$ full; $2=50 \%$ full; $3=$ $75 \%$ full; 4 = completely full), and stage of prey item digestion was estimated on a scale of 1 to 3 (1 = highly digested, completely transparent; $2=$ partially digested; 3 = undigested, some color remains) (Young \& Davis 1990).
In order to analyse relationships between prey width (PW) and larval size (SL and MW), the larvae were classed in size intervals to produce the maximum number of size classes containing 3 or more prey items. To fit this requirement, an interval of $0.12 \mathrm{~mm}$ was used for SL and $0.01 \mathrm{~mm}$ for MW. Relationships were estimated by linear regression analysis of $\log _{10}$-transformed PW vs. larval size (weighted by the number of prey items per larval size class) (log PW $=b+a \mathrm{SL})$. As in previous studies, the SD of the $\log _{10}$-transformed prey size was taken as a measure of trophic niche breadth (Pearre 1985). The fitted lineal model is equivalent to the exponential model: $\mathrm{PW}=10^{b} \exp [k \mathrm{SL}]$, where $k=a \ln 10$. The deriv-
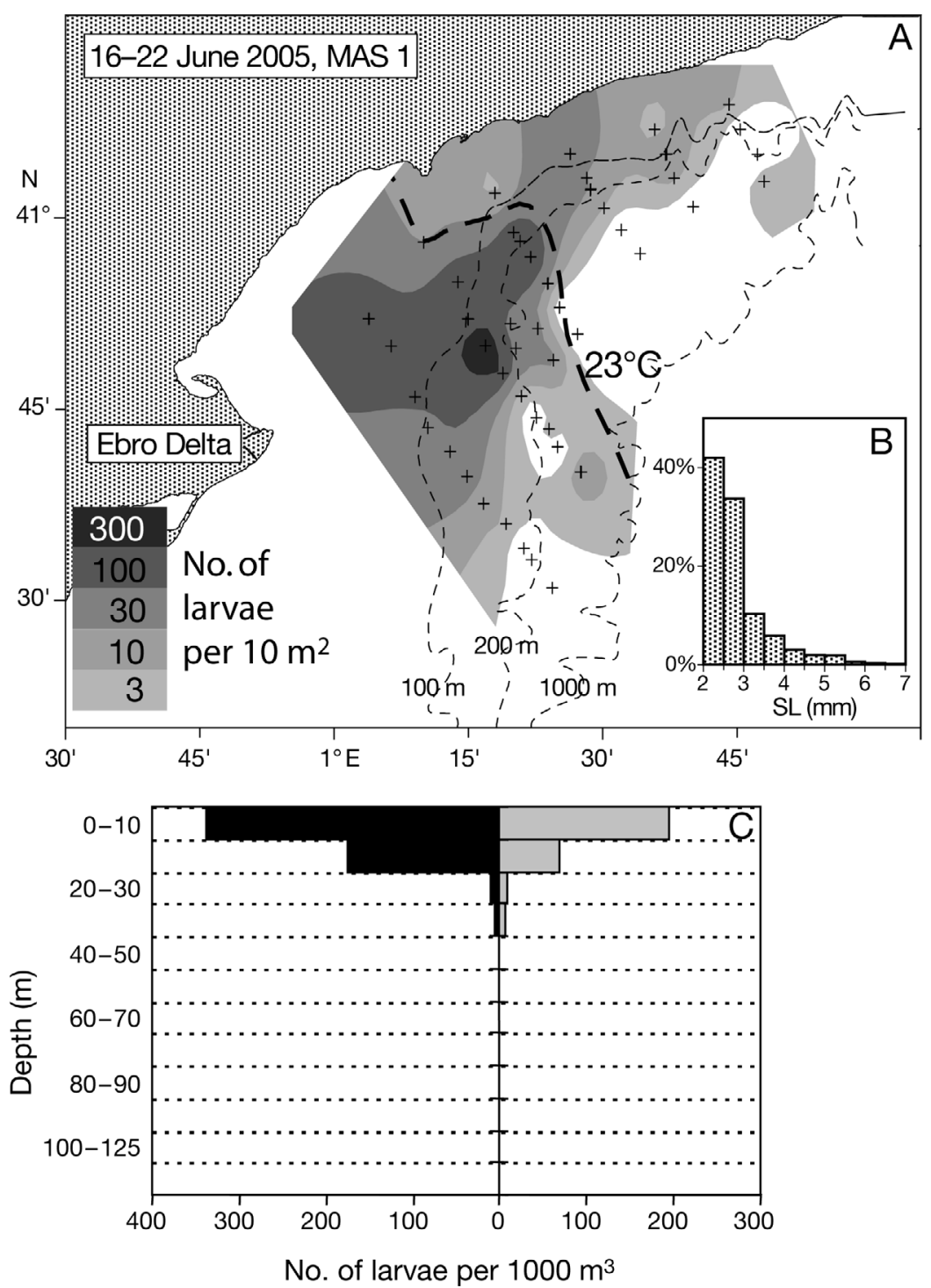

Fig. 1. Auxis rochei larvae. (A) Horizontal distribution during MAS 1 survey; broken black line depicts the $23^{\circ} \mathrm{C}$ isotherm. (B) Larval size frequency distribution; SL = standard length. $(\mathrm{C})$ Mean vertical distribution obtained from Longhurst Hardy Plankton Recorder hauls during the day (grey bars) and at night (black bars). (+): sampled stations 
ative of the exponential equation $(\mathrm{dPW} / \mathrm{dSL}=k \mathrm{PW})$ demonstrates that $k$ can be interpreted as the relative rate of change in prey size with respect to larval size.

The diet was described using the percentage frequency of occurrence $(\% \mathrm{~F})$ of a diet item in larvae with food in their guts and the percentage frequency of the total number $(\% \mathrm{~N})$ of diet items examined. The product of these 2 values was taken as the percentage index of relative importance of each diet item (\%IRI) (Govoni et al. 1986). The Shannon-Weaver diversity index $\left(H^{\prime}\right)$ was used as a measure of prey diversity in the gut.

Prey taxon selection by larvae $(\mathrm{n}=92, \mathrm{SL}=2.1$ to $6.3 \mathrm{~mm}$ ) was determined using the alpha index (Chesson 1978) calculated for individual larvae by prey item and averaged by $1 \mathrm{~mm}$ larval size class, except for the final size class, which encompassed larvae ranging from 5 to $6.3 \mathrm{~mm}$ in length. Only the 9 most common food organisms were considered: neutral selection would thus result in a constant $\alpha=1 / 9$.

The carbon equivalent mass of prey items in the gut was estimated from species-specific length-weight relationships obtained from the literature, assuming when necessary a carbon content equal to $40 \%$ of dry weight. We used equations from Menden-Deuer \& Lessard (2000) for phytoplankton, Putt \& Stoecker (1989) for tintinnids, Kleppel et al. (1991) for copepod eggs and other eggs, Hay et al. (1988) for copepod nauplii and postnauplii (using equations developed for Pseudocalanus elongatus), Catalán et al. (2007) for Evadne spp., and López-Urrutia et al. (2003) for appendicularians. A conservative $12 \mu \mathrm{g} C$ per fish larva ingested was used ( $40 \%$ of the dry weight of a $4 \mathrm{~mm}$ long anchovy larva). The relationship between larval carbon content in the gut and larval size was examined. The larvae were again classed by $0.12 \mathrm{~mm}$ SL intervals and the size classes grouped, with cumulative gut contents of at least 3 larvae as a groupforming requirement. The mean and standard deviation for the $\log _{10}$-transformed values of total $\mathrm{C}$ content were calculated for each larval size class. Linear regression analysis was performed, weighted by the number of larvae.

\section{RESULTS}

\section{Larval fish distribution and environment}

Auxis rochei larvae were regularly present all along the continental shelf in the study area, with principal concentrations in the SW sector, where sea surface temperature (SST) was higher (Fig. 1A). Larval size ranged from 2 to $7 \mathrm{~mm}$ SL, with more than $70 \%$ of larvae measuring $\leq 3 \mathrm{~mm}$ (Fig. 1B). The vertical distribution of the larvae of this species was restricted to the top $20 \mathrm{~m}$ of the water column (Fig. 1C).

The microplankton in the sample tows consisted mainly of small dinoflagellates, tintinnids and copepod nauplii (Fig 2). Such meroplanktonic taxa as polychaete, bivalve and gastropod larvae were also abundant in this fraction. Copepod postnauplii and appendicularians were abundant in the micro- and mesoplankton. Cladocerans (mainly Evadne spp.), doliolids and cnidarians were the other abundant components of the mesoplankton.

\section{Feeding incidence and diel pattern}

The smallest larva with food in the gut measured $2.1 \mathrm{~mm}$. The diel feeding pattern evidenced diurnal activity, increasing from sunrise. FI was $87.6 \%$ during the daytime, whereas only $19 \%$ of the larvae had food

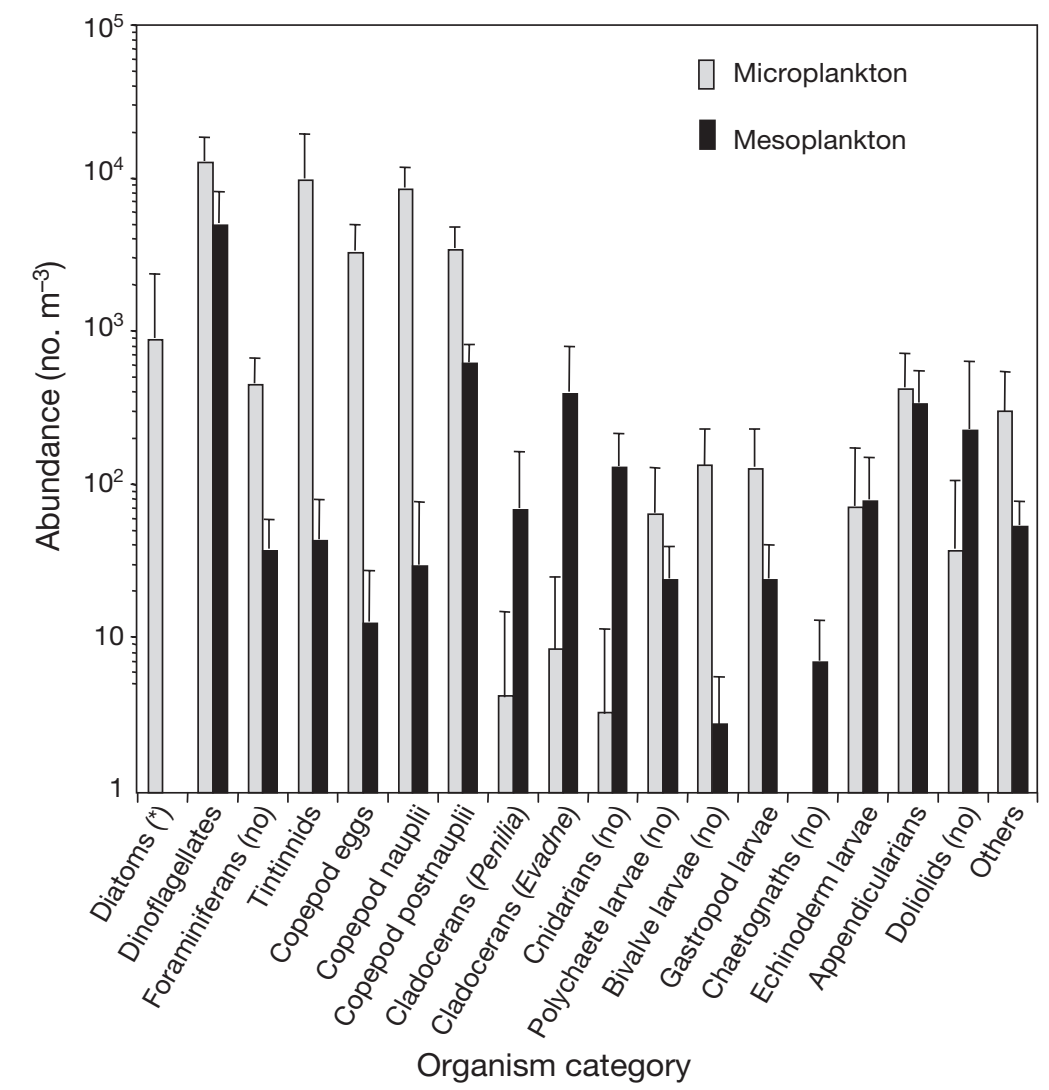

Fig. 2. Planktonic organisms. Mean abundance and standard deviation values of micro- and mesoplanktonic organisms at the 18 stations used for prey availability and larval feeding selectivity analysis. $\left({ }^{*}\right)=$ organisms not quantified in the mesoplanktonic fraction. (no) = organisms not found in larval gut contents 
in their guts at night, and these prey items were in advanced stages of digestion. No differences in FI were observed with larval size either during the daytime or at night (ANOVA, $p>0.05)$. The number of prey items per larva ranged from 0 to $13(5 \pm 3.3)$, with the number peaking in the 14:00 to $18: 00 \mathrm{~h}$ interval and falling off sharply after sunset (Kruskal-Wallis, $\mathrm{p}<$ 0.001) (Fig. 3). Because of this daytime feeding pattern, only larvae collected during hours of daylight with identifiable prey items (130 larvae; $\mathrm{SL}=2.1-6.3 \mathrm{~mm}$ ) were considered in subsequent analyses.

The highest gut fullness value, around $75 \%$, was recorded between 14:00 and 18:00 h (ANOVA, p < 0.001). Gut fullness stayed at around $50 \%$ during the rest of the hours of daylight. The digestion state of prey items varied significantly only between 10:00 and 14:00 $\mathrm{h}$, when prey items were in the early stages of digestion, and between 14:00 and 18:00 h, when they were in a more advanced stage of digestion (KruskalWallis, $\mathrm{p}<0.05$ ).

\section{Predator-prey relationship}

The number of prey items ingested increased slightly from the early larval stage to a larval length of $4 \mathrm{~mm}$ SL, followed by a slight decrease (Fig. 4). PW ranged from 5 to $620 \mu \mathrm{m}$. In the larvae measuring $<3 \mathrm{~mm}, 80 \%$ of the prey items ingested were less than $100 \mu \mathrm{m}$ wide, and the rest of the prey items were between 200 and $300 \mu \mathrm{m}$. In contrast, in the largest larvae (between 5 and $7 \mathrm{~mm}$ ), the width of $80 \%$ of the ingested prey items ranged from 100 to $500 \mu \mathrm{m}$ (Kruskal-Wallis, p < 0.001) (Fig. 5).

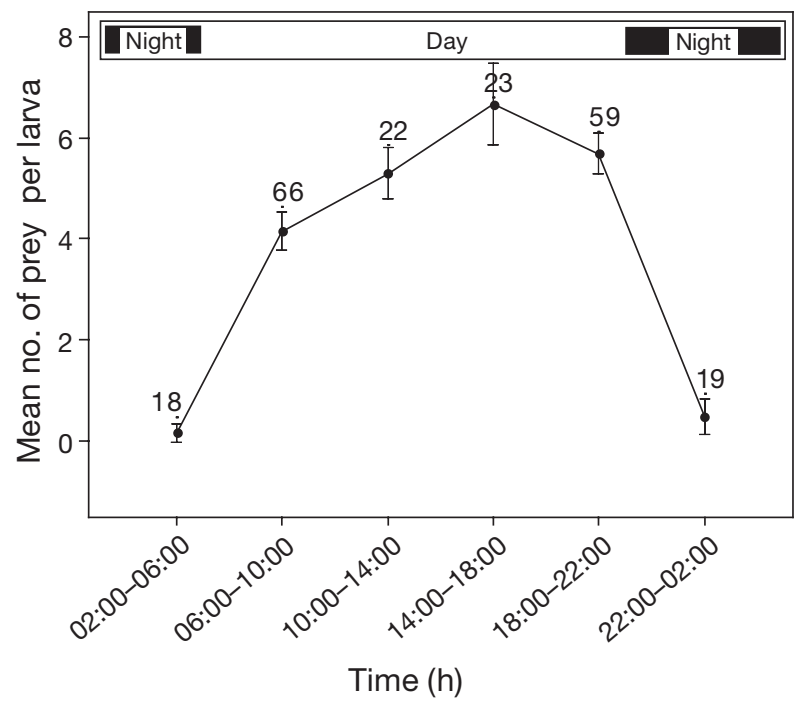

Fig. 3. Auxis rochei larvae. Mean number of prey per gut $( \pm 2 \mathrm{SE})$ as a function of local time (h). Values above the data points indicate number of larvae examined

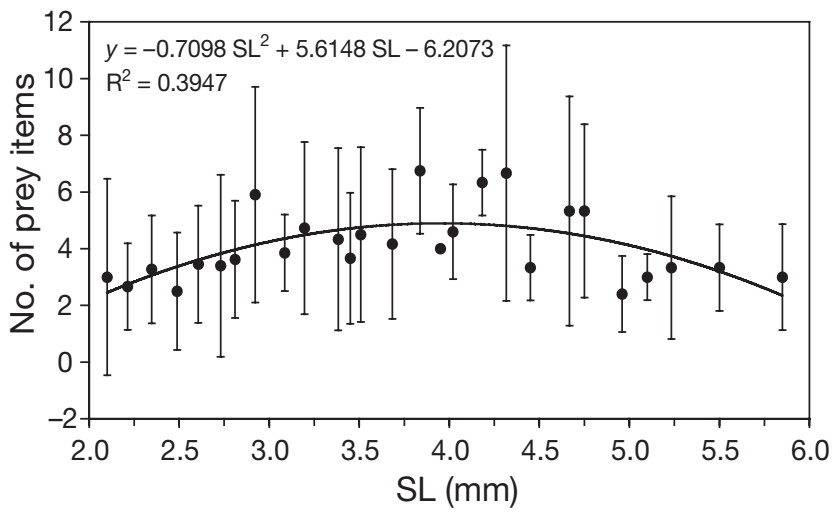

Fig. 4. Auxis rochei larvae. Mean number of prey items per gut $( \pm \mathrm{SD})$ plotted against larval standard length (SL)

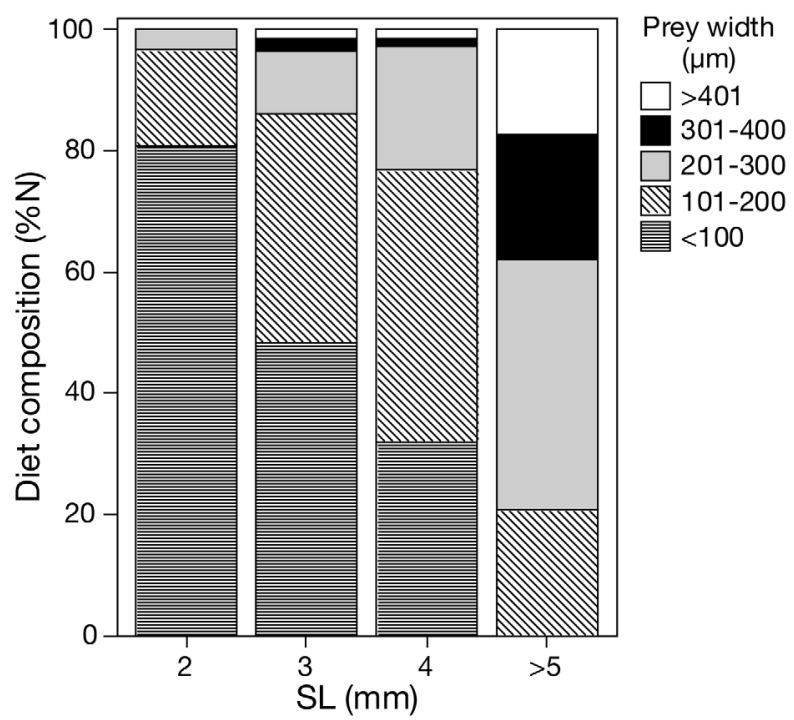

Fig. 5. Auxis rochei larvae. Cumulative percentage composition of the diet $(\% \mathrm{~N})$ by prey item width class in relation to larval standard length (SL)

The weighted regressions for mean log size of prey items on larval SL and MW had positive slopes and significant correlations ( $p<0.001$ ) (Fig. 6A,B). The rate of change of prey size was $0.5 \mathrm{~mm}^{-1}$ with increasing SL and $2.6 \mathrm{~mm}^{-1}$ with MW. Regression analysis yielded high residual sum of squares error, but even so, the relationship between niche breadth and SL underwent a slight decrease in larvae with SL > 5 mm (Fig. 6C).

\section{Diet and selectivity}

Prey diversity $\left(H^{\prime}\right)$ was highest in the larvae with SL $<4 \mathrm{~mm}$ (Table 1), whose gut contents included phytoplankton, tintinnids, copepod eggs, and gastropod and echinoderm larvae, none of which were recorded in 

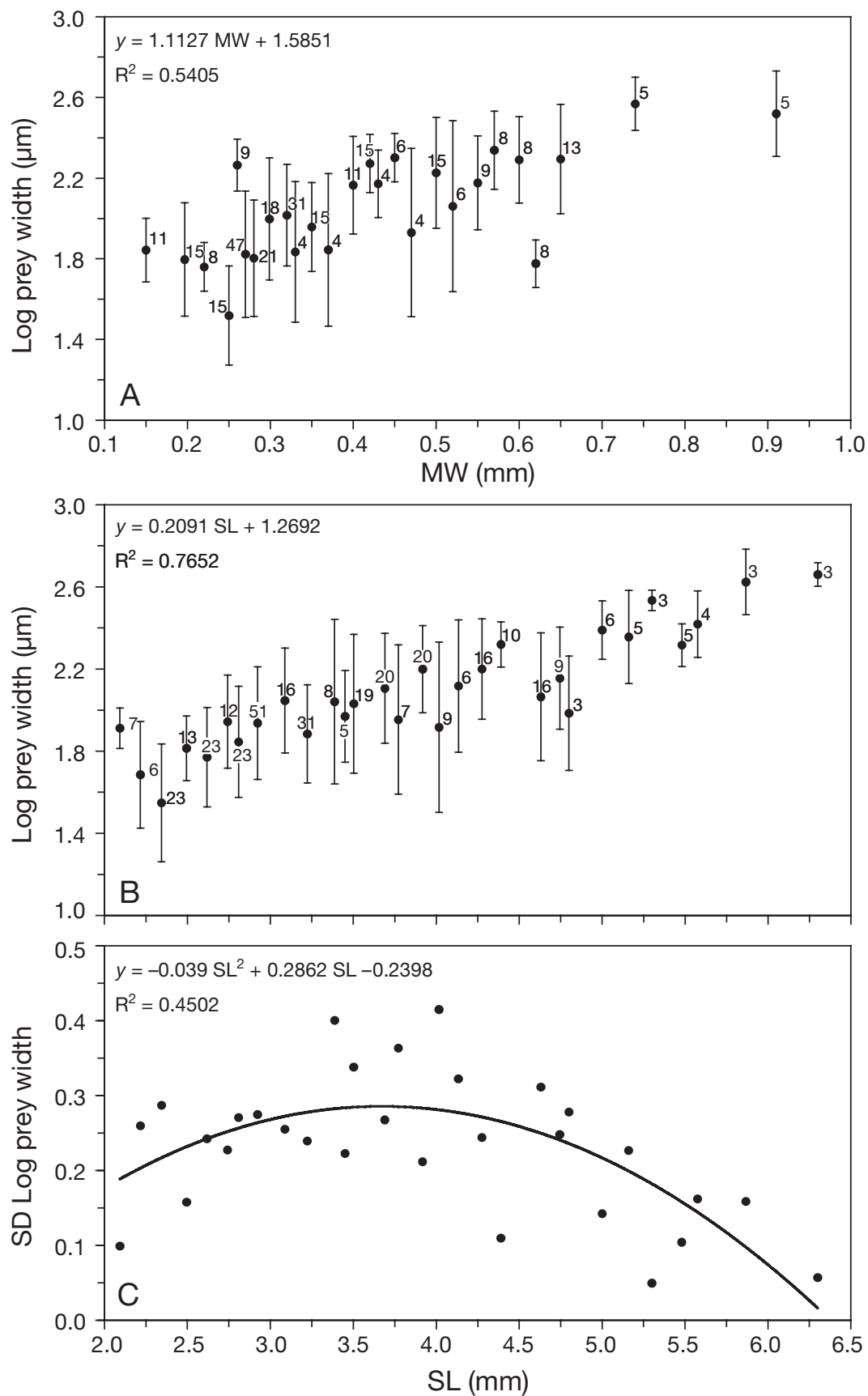

Fig. 6. Auxis rochei larvae. Logarithmic mean prey item width $( \pm \mathrm{SD})$ in relation to larval (A) mouth width (MW) and (B) standard length (SL). Numbers to the right of the data points in (A) and (B) indicate number of prey items per larval size class. Weighted regressions (weighted by number of prey items per size class) shown above each plot. (C) Niche breadth, expressed as SD log of prey width, plotted against larval SL

the larger larvae. The IRI demonstrated differences between larvae with $\mathrm{SL}<4 \mathrm{~mm}$ and those with $\mathrm{SL}>$ $4 \mathrm{~mm}$. Copepod nauplii were the most frequent and most abundant prey items in larvae with $\mathrm{SL}<4 \mathrm{~mm}$ (IRI $40.4 \%$ ), compared with cladocerans in larvae with SL > $4 \mathrm{~mm}$ (IRI 52.6\%) (Table 1). Larval fish prey items were observed in the larger larvae, especially in larvae with $\mathrm{SL}>5 \mathrm{~mm}$.

Selectivity for particular taxa was evident when the gut content was analysed as a function of available prey. Larvae with SL $<3$ mm selected mainly copepod nauplii and other small prey items like phytoplankton, gastropod larvae, copepod eggs, and small postnauplii, while selecting against tintinnids, cladocerans, appendicularians, and fish larvae. Larvae with SL from 3 to $4.9 \mathrm{~mm}$ preferred cladocerans and appendicularians, along with copepod nauplii to a lesser extent, and avoided other prey. The larger larvae with SL from 5 to $6.3 \mathrm{~mm}$ positively selected appendicularians and fish larvae, while their preference for cladocerans declined (Fig. 7).

The carbon content in the gut (log transformed) was significantly correlated with larval size. Higher increases were recorded both in the youngest larvae from the onset of feeding (with $\mathrm{SL}<3 \mathrm{~mm}$ ) and in larvae with $\mathrm{SL}>5 \mathrm{~mm}$ (Fig. 8).

\section{Development of feeding organs}

Larvae undergo pronounced mouth development with a significant positive allometric relationship to body length (Table 2, Fig. 9). The first dentary teeth appear at around $3 \mathrm{~mm} \mathrm{SL}$ and the first premaxillary teeth at $4 \mathrm{~mm}$ SL. The number of teeth present was higher for larvae with SL > $5 \mathrm{~mm}(5.4 \pm 1.96)$ and pharyngeal teeth were also observed. Tooth morphology was sharp and conical, except for a few specialized hooklike dentary teeth in larvae with SL > $5 \mathrm{~mm}$.

The external morphology of whole, fixed larvae with SL $<3 \mathrm{~mm}$ revealed a digestive tract consisting of a simple tube (with fore- and hindgut regions apparently separated by a gastric valve), which was looped in larvae with $\mathrm{SL} \geq 3 \mathrm{~mm}$. This coincided with development of a protrusion at the end of the foregut (the presumptive incipient stomach). Histological examination of late flexion larvae confirmed that development of the stomach had commenced, with gastric glands and pyloric caecae present; however, pyloric caecae 
Table 1. Auxis rochei larvae diet. SL = standard length, $\mathrm{N}=$ number, $H^{\prime}=$ prey diversity index. $\% \mathrm{~F}=$ percentage occurrence in the gut, $\% \mathrm{~N}=$ percentage abundance of prey items, $\mathrm{IRI}=\left(\% \mathrm{~F}^{*} \% \mathrm{~N}\right), \mathrm{PN}=$ prey number (range)

\begin{tabular}{|lcccc|}
\hline Prey items & $\% \mathrm{~F}$ & $\% \mathrm{~N}$ & IRI $(\%)$ & $\mathrm{PN}$ \\
\hline SL $<$ 4 mm (N = 89, $\left.H^{\prime}=2.235\right)$ & & & \\
Phytoplankton & 10.29 & 8.12 & 7.11 & $0-3$ \\
Tintinnids & 6.62 & 5.98 & 3.37 & $0-3$ \\
Gastropod larvae & 4.41 & 6.41 & 2.40 & $0-6$ \\
Copepod eggs & 6.62 & 5.56 & 3.13 & $0-2$ \\
Copepod nauplii & 19.85 & 23.93 & 40.40 & $0-7$ \\
Copepod postnauplii & 7.35 & 5.56 & 3.47 & $0-4$ \\
Copepod fragments & 0.74 & 0.43 & 0.03 & \\
Cladocerans & 7.35 & 12.39 & 7.75 & $0-9$ \\
Crustacean fragments & 14.71 & 14.10 & 17.63 & \\
Appendicularians & 12.50 & 11.97 & 12.72 & $0-4$ \\
Echinoderm larvae & 0.74 & 0.43 & 0.03 & $0-1$ \\
Other eggs & 5.15 & 2.99 & 1.31 & $0-4$ \\
Fish larvae & 0 & 0 & 0 & 0 \\
Others & 3.68 & 2.14 & 0.67 & $0-1$ \\
SL $>$ 4 mm (N = 40, $\left.H^{\prime}=1.619\right)$ & & & \\
Phytoplankton & 0 & 0 & 0 & 0 \\
Tintinnids & 0 & 0 & 0 & 0 \\
Gastropod larvae & 0 & 0 & 0 & 0 \\
Copepod eggs & 0 & 0 & 0 & 0 \\
Copepod nauplii & 19.23 & 17.78 & 16.70 & $0-6$ \\
Copepod postnauplii & 5.77 & 3.33 & 0.94 & $0-1$ \\
Copepod fragments & 1.92 & 1.11 & 0.10 & \\
Cladocerans & 26.92 & 40.00 & 52.61 & $0-6$ \\
Crustacean fragments & 15.38 & 12.22 & 9.19 & \\
Appendicularians & 19.23 & 18.89 & 17.75 & $0-3$ \\
Echinoderm larvae & 0 & 0 & 0 & 0 \\
Other eggs & 1.92 & 1.11 & 0.10 & $0-1$ \\
Fish larvae & 9.62 & 5.56 & 2.61 & $0-1$ \\
Others & 0 & 0 & 0 & $0-1$ \\
\hline
\end{tabular}

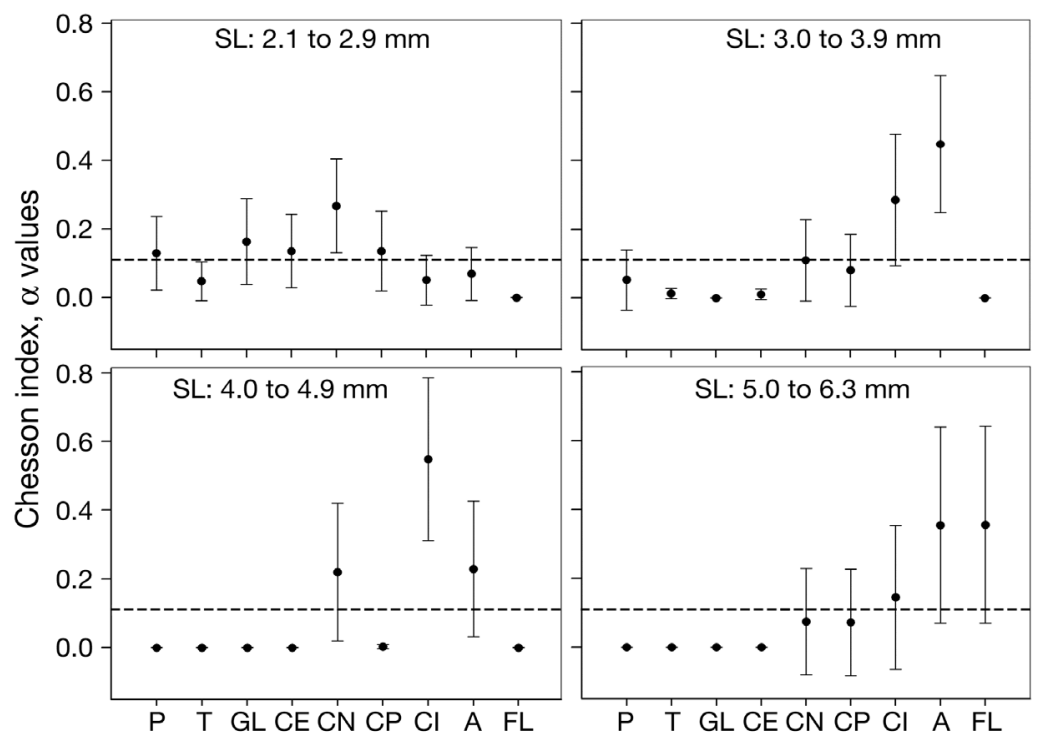

Fig. 7. Auxis rochei larvae. Mean Chesson's $\alpha$ values $( \pm 95 \%$ confidence interval) for the most common prey items in larvae of different size classes; SL: standard length. Circles above the dashed line indicate positive selection. P: phytoplankton; T: tintinnids; GL: gastropod larvae; CE: copepod eggs; $\mathrm{CN}$ : copepod nauplii; $\mathrm{CP}$ : copepod postnauplii; $\mathrm{Cl}$ : cladocerans - Evadne spp.; A: appendicularians; FL: fish larvae were still very few in the largest larvae examined (SL $=7 \mathrm{~mm})$, and digestion vacuoles were present only in the intestine and rectum but not in the developing stomach (Fig. 10).

Eye and lens diameter increased from a minimum of 0.255 and $0.095 \mathrm{~mm}$, respectively, in a $2.6 \mathrm{~mm}$ SL larva to a maximum of 0.770 and $0.270 \mathrm{~mm}$, respectively, in a $7 \mathrm{~mm}$ SL larva. The retina was differentiated in all larvae in the size range analysed, as evidenced by the presence of the outer nuclear layer (ONL), inner nuclear layer (INL), ganglion cell layer (G), and connecting fibre layers (the inner and outer plexiform layers and optic fibre layer) (Fig. 11A). In addition, the retinal epithelium layer (REP) was pigmented, the optic nerve connected to the optic tectum, and lens crystallization was apparent. Just single cones were present in preflexion larvae. Angular density of cones increased with larval growth (Fig. 12) (Kruskal-Wallis, $\mathrm{p}<0.05)$, with no differences among the regions of the central retina examined. Cone photoreceptor outer segment length was higher in the dorsal region than in the ventral and middle regions, irrespective of larval stage (ANOVA, p < 0.05). The presence in the outer nuclear layer of dark-staining, irregularly shaped nuclei in a vitread position relative to the lighter-staining cone nuclei (presumptive rod photoreceptor precursors or nuclei) was noted in a $4.5 \mathrm{~mm}$ SL larva. This cell type increased during larval flexion, reaching higher densities in the dorsal retinal region (Fig. 12) (Kruskal-Wallis, $\mathrm{p}<0.05$ ). Tangential sections of a late flexion larva ( $\mathrm{SL}=6 \mathrm{~mm}$ ) revealed the presence of both double and single cone photoreceptors arranged in an organized pattern of double cones surrounding a single cone. No double cones were observed in smaller larvae with SL from 4.9 to $5.4 \mathrm{~mm}$.

\section{DISCUSSION}

Auxis rochei larvae with SL from 2 to $7 \mathrm{~mm}$ are diurnal feeders, a fact reflected in the small number of prey items and the advanced stage of digestion of those items in the larval gut at night and consistent with a strong reliance upon visual prey detection by these larvae. This feeding pattern is shared by many other species (Hubbs \& Blaxter 1986) and agrees with the results for Auxis spp. in the Gulf of California published by Sánchez-Velasco et al. (1999).

Larvae of this species are voracious feeders. Not only did they feed continuously (gut fullness $>50 \%$ during day- 


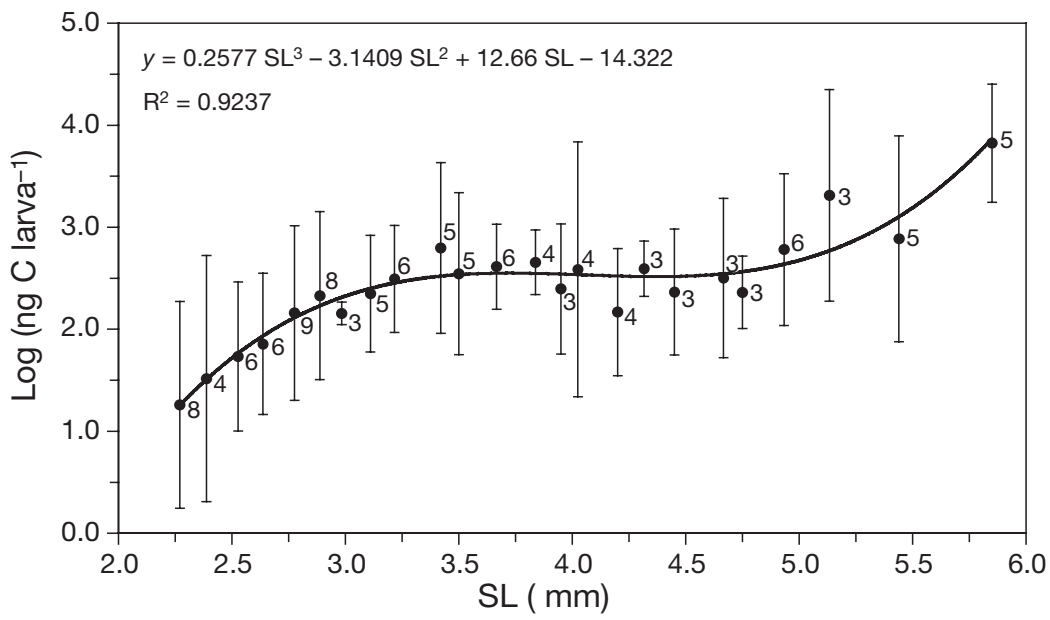

Fig. 8. Auxis rochei larvae. Weighted regressions of logarithmic mean carbon equivalent content in the larval gut $( \pm \mathrm{SD})$ plotted against larval standard length (SL). Numbers to the right of the data points indicate the number of larvae in size class

A

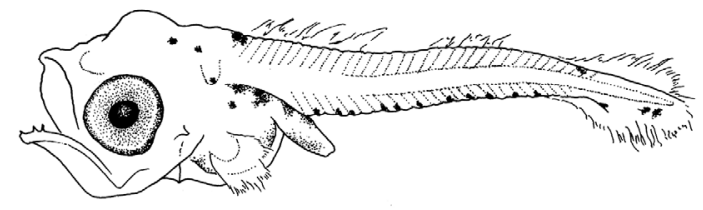

B
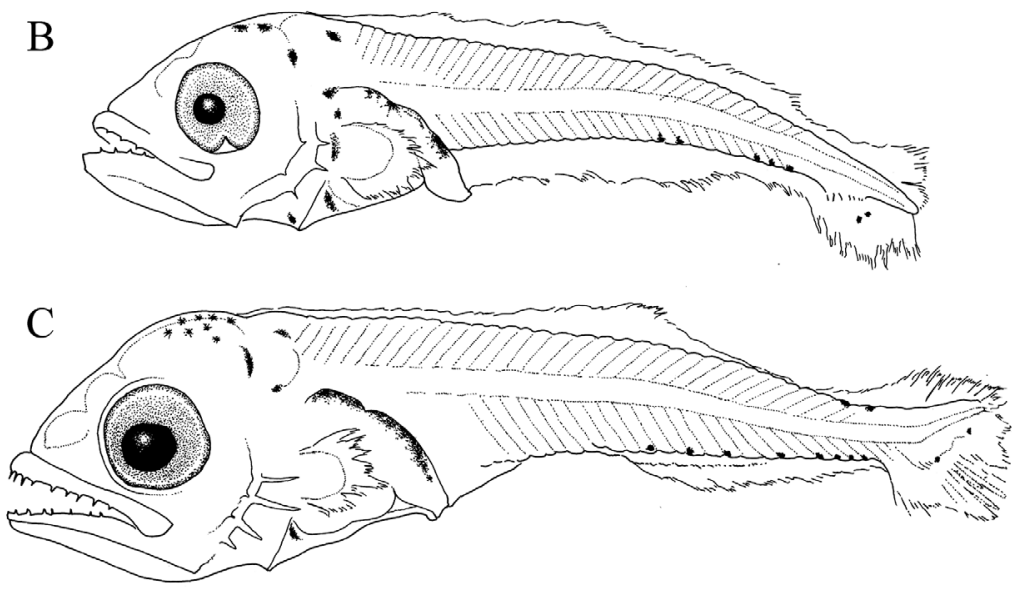

Fig. 9. Auxis rochei larvae. (A) Early feeding stage, SL $=2.9 \mathrm{~mm}$. (B) Early flexion stage, $\mathrm{SL}=4.9 \mathrm{~mm}$. (C) Late flexion stage, $\mathrm{SL}=7 \mathrm{~mm}$

Table 2. Auxis rochei larvae. Regression parameters and statistics for the relationships between lower jaw length (LJL), upper jaw length (UJL), mouth width (MW), and eye diameter (ED) vs. larval standard length (SL), with $\mathrm{r}^{2}$ values and number of data points (n). Confidence interval (CI) $95 \%$

\begin{tabular}{|lccc|}
\hline Model & CI of slope & \multicolumn{1}{c}{$\mathrm{r}^{2}$} & $\mathrm{n}$ \\
\hline $\mathrm{LJL}=0.075 \mathrm{SL}^{1.4203}$ & 0.1008 & 0.8154 & 177 \\
$\mathrm{UJL}=0.0637 \mathrm{SL}^{1.5251}$ & 0.1111 & 0.8012 & 184 \\
$\mathrm{MW}=0.0651 \mathrm{SL}^{1.3657}$ & 0.0998 & 0.8019 & 182 \\
$\mathrm{ED}=0.1223 \mathrm{SL}^{0.9552}$ & 0.0495 & 0.89 & 181 \\
\hline
\end{tabular}

light), but they also had much higher FI, gut fullness, and prey number values than the larvae of clupeiform and myctophiform teleost fishes (e.g. Tudela et al. 2002, Sassa \& Kawaguchi 2004), and even of other tunas (Margulies 1993, SánchezVelasco et al. 1999). This is related to Auxis rochei larval morphology, i.e. a large, looped gut, large mouth, and large eyes. The looping helps retain prey, and even though the stomach was not functional in the size range studied, the presence of pinocytotic vesicles indicates that digestion was actively taking place in the gut.

\section{Predator-prey relationship}

Predator-prey relationships were analysed using log-transformed PW vs. SL or MW according to Pearre (1985). PW was used because there is evidence that prey length is not a critical factor in the ingestion of some prey items, while MW was chosen because it is closely correlated with the ability to capture prey and is a more accurate measurement than mouth gape (Hunter 1981).

Mean prey size increased with larval size, as it does in most species (Hunter 1981), but the rate of change in prey size with Auxis rochei larval size was higher than in other large-mouthed species like myctophids (Sabatés \& Saiz 2000, Sassa \& Kawaguchi 2004) and other tunas (Catalán et al. 2007), indicating that prey catching ability develops faster in this species. The greatest niche breadth was observed for the larvae with SL of ca. $4 \mathrm{~mm}$ and decreased in larger larvae. The reason for this is that the upper and lower limits on prey size do not increase the same way. Maximum prey size rises quite quickly up to a larval size of $4 \mathrm{~mm} \mathrm{SL}$, and then slows down. Minimum prey size holds constant until $5 \mathrm{~mm}$ SL and then increases. The lower niche breadth values in the larger larvae, combined with lower prey diversity, are indicative of a more selective foraging pattern, avoiding smaller prey items in favour of larger ones. Not only is this a better feeding strategy in that it concentrates on prey items with a higher energy content, but it also helps reduce competition with smaller larvae (Pearre 1985, GonzálezQuirós \& Anadón 2001). 

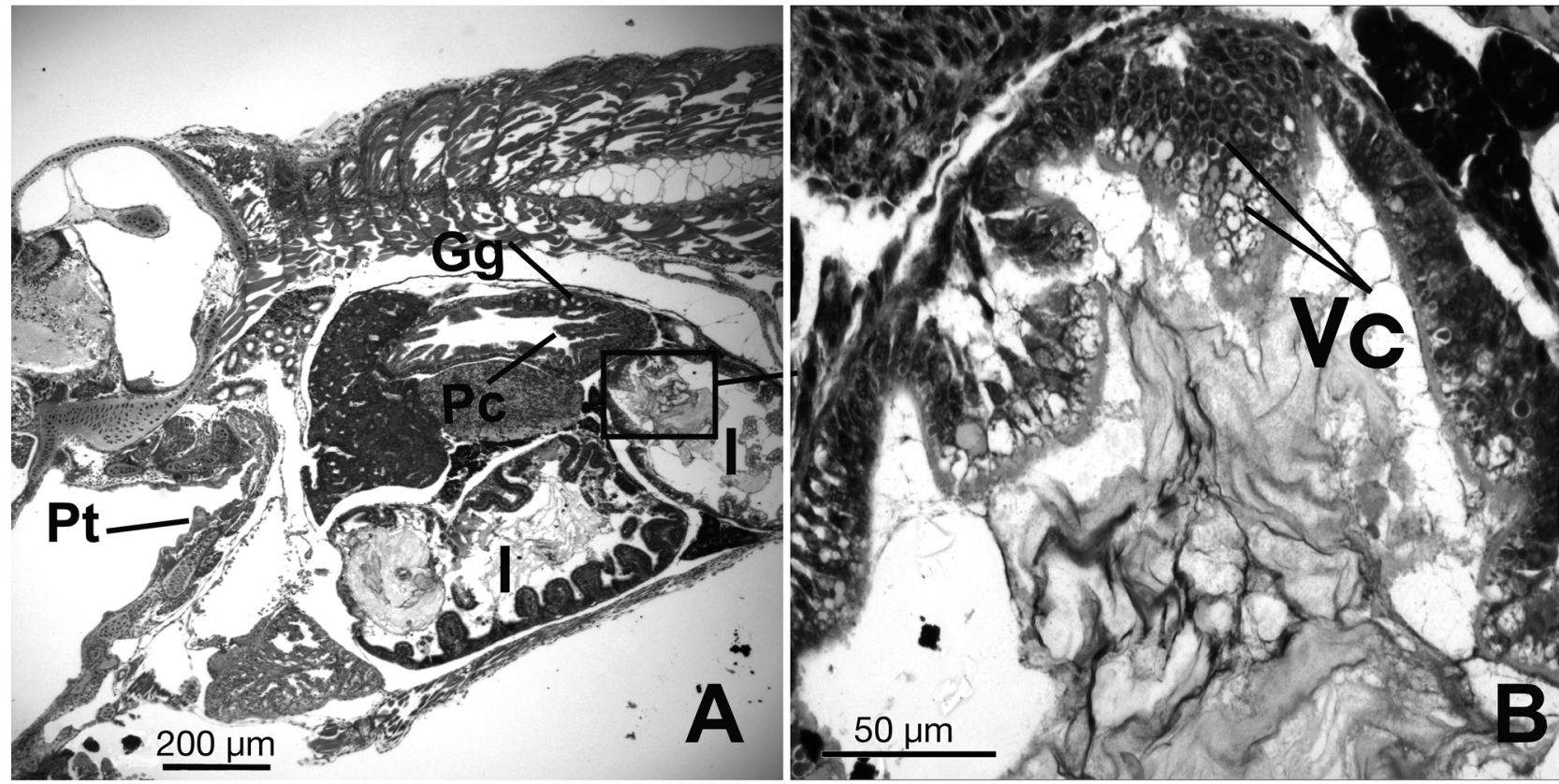

Fig. 10. Auxis rochei larva, SL $=7 \mathrm{~mm}$. (A) Sagittal section photomicrograph of the body axis showing the digestive tract; Gg: gastric glands, Pc: pyloric caecum, Pt: pharyngeal teeth, I: intestine. (B) Detail of the intestine (I) showing different types of vacuoles $(\mathrm{Vc})$
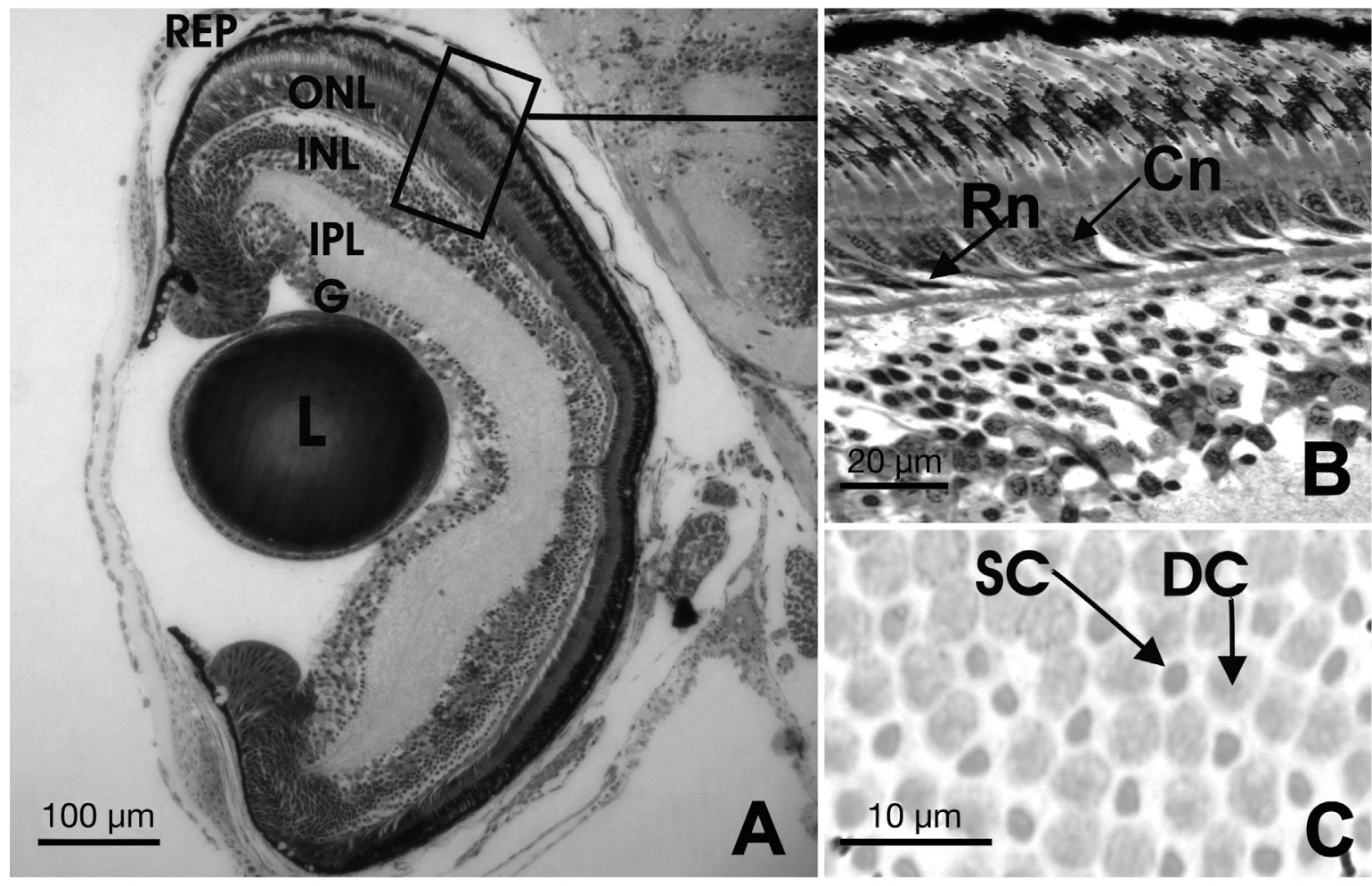

Fig. 11. Late flexion Auxis rochei larva. (A) Transverse section photomicrograph: layers of the eye of a $6.5 \mathrm{~mm}$ SL larva; REP: retinal epithelial pigment, ONL: outer nuclear layer, INL: inner nuclear layer, IPL: inner plexiform layer, G: ganglion cell layer, L: lens. Optic fibre layer not visible. (B) Outer nuclear layer of the dorsal area of the central retina of the same larva showing cone nuclei $(\mathrm{Cn})$ and rod precursor nuclei (Rn). (C) Tangential section photomicrograph of the eye of a $6 \mathrm{~mm}$ SL larva showing double cones (DC) surrounding single cones (SC) 


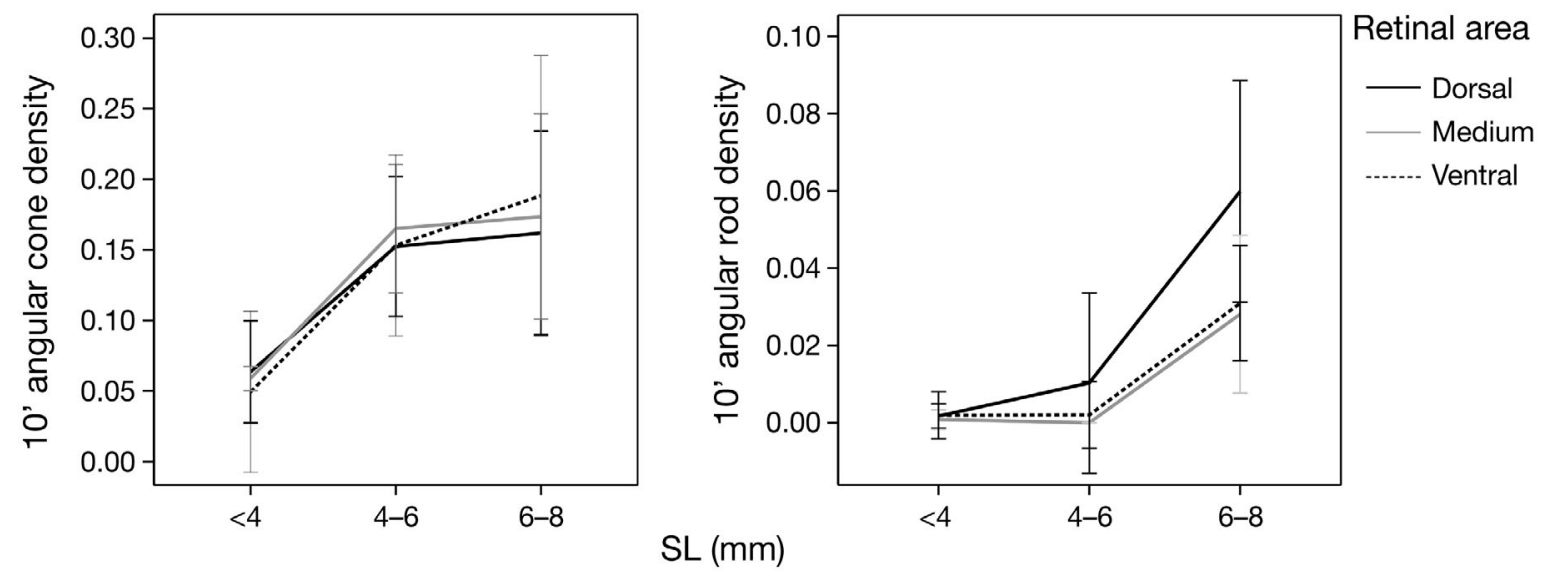

Fig. 12. Auxis rochei larvae. Developmental change in angular photoreceptor density (cones and rods). SL: standard length. Values are mean \pm SD

\section{Diet and selectivity}

As in other species (Last 1980), Auxis rochei preflexion larvae are more euryphagous and eat certain types of prey that larger larvae later avoid, i.e. phytoplankton, tintinnids (above all Undella hyalina), gastropod larvae, and copepod eggs. In contrast, larvae with SL > $4 \mathrm{~mm}$ prefer larger, more mobile prey, like cladocerans (mostly Evadne spinifera), appendicularians, and fish larvae. Selection for cladocerans as opposed to copepods of similar size when both types of prey are available could be due to their yelloworange color and large, pigmented eye, which makes them more visible (Govoni et al. 1986). Uotani et al. (1981) also reported positive selection for appendicularians and cladocerans (Evadne sp.) by Auxis $\mathrm{sp}$. in the Indian Ocean. A finding to note was the relative absence of copepod postnauplii, a typical diet item in most marine fish postflexion larvae (Last 1980), including Auxis sp. larvae in the Gulf of California (Sánchez-Velasco et al. 1999) and the larvae of such other tuna species as Thunnus alalunga (Catalán et al. 2007) and Thunnus maccoyii (Young \& Davis 1990).

The fact that appendicularians are important in the diet of Auxis rochei larvae in the Mediterranean is clear not only because of their frequency and abundance in the larval gut but also because larvae with SL $>3 \mathrm{~mm}$ selected for them. A number of researchers have noted the importance of soft prey items like appendicularians in the diets of the larvae of some scombrids like Katsuwomus pelamis (Uotani et al. 1981). Unlike the rest of the gelatinous zooplankton, the carbon content of appendicularians is similar to that of copepods (Hay et al. 1988, López-Urrutia et al. 2003). This prey species could be selected because of its slow, undulating movement, which may attract predators, and though they are large and elongate, their softness means that they are easily eaten and digested.

While piscivory appears to be widespread from the very early stages in other scombrids like Scomber spp. and Scomberomorus spp. (Conway et al. 1999, Shoji \& Tanaka 2001), positive selection for larval fish was only observed in Auxis rochei larvae with SL $>5 \mathrm{~mm}$, concomitant with greater tooth development, the appearance of specialized teeth, and flexion of the urostyle. All these attributes help make larvae more capable of both catching and handling and eating this type of prey.

The carbon content in the guts of the larvae over the course of larval development followed a rising trend, especially because of the paucity of the gut contents in some onset feeding larvae and the contribution of fish larvae to the diet in the larvae in the larger larval size intervals. Even though fish larvae were a lesser component in the diet of Auxis rochei larvae, their relatively high carbon content makes piscivory a determining factor in achieving high larval growth rates, because it raises the carbon content in the gut by an order of magnitude. Daily growth rates of piscivorous larvae are among the highest reported for teleost fishes (Tanaka et al. 1996 and references cited therein).

Precocious digestive systems have been observed in early piscivorous larvae like Scomberomorus spp. (Tanaka et al. 1996). Feeding habits and digestive system ontogeny in Auxis rochei are similar to Katsuwomus spp., i.e. an intermediate habit between strict zooplanktivory and piscivory (Uotani et al. 1981, Young \& Davis 1990). The soon-to-be functional stomach in the largest $A$. rochei larvae, together with the increasing importance of fish larvae in the diet, suggests that piscivory will be important in the next developmental stages. 


\section{Vision enhancement}

The retina appears functional in the smallest larvae examined, coinciding with the high FI values for these larvae during the daytime. This is consistent with a single type of retinal photoreceptor, single cones, which provide for acute visual discrimination, such as the visual detection of prey, but which limit vision to relatively high light intensity conditions in well lit 'surface' waters during the day (photopic acuity) (Hubbs \& Blaxter 1986). The presence of both double and single cones in flexion stage Auxis rochei larvae ( $\mathrm{SL}=6 \mathrm{~mm}$ ) provides evidence for an ontogenetic increase in visual discrimination under lower light intensity conditions in daytime (photopic sensitivity), since double cones have larger surface areas for light capture (and therefore a greater likelihood of photoreceptor stimulation) than their smaller-diameter single cone counterparts (Lythgoe et al. 2004). Photopic sensitivity is also likely to be enhanced by the ontogenetic increase in cone photoreceptor outer segment lengths, which provide a longer light path for image forming light to successfully achieve photoreceptor stimulation. Whether preflexion stage $A$. rochei larvae are capable of color vision is unknown. Previous studies have determined that the single cone retinae of many species of fish larvae have a range of single cones with different spectral absorption maxima; however, these occur later in larval development and most fish that hatch with a single cone retina have only green and possibly UV sensitivity, which is a limited color vision system (Britt et al. 2001). Ontogenetic increases in the eye and corresponding lens size result in increased visual acuity because, under optimal illumination conditions, an object viewed from a given distance by one fish with a smaller and another with a larger eye potentially stimulates more photoreceptors in the larger eye during image formation, with a resulting increase in acuity (Hairston et al. 1982). This means that given optimal visual conditions of water clarity and light brightness, larger larvae will be able to discriminate objects at greater distances (Breck \& Gitter 1983). Rod photoreceptors and/or their precursors were evident in early flexion $A$. rochei larvae, with angular densities of rods increasing thereafter, thus providing for increasing visual function under conditions of dim monochromatic light at night or at depth during the daytime (scotopic sensitivity) (Hubbs \& Blaxter 1986). This is consistent with another study in which rods were first noted in $7 \mathrm{~mm}$ SL larvae of Auxis spp. (Margulies 1997), where it was suggested that development of rod vision could play an important role in predator avoidance. While cone density in $A$. rochei did not vary with the retinal region examined, the fact that cone outer segment lengths and rod densities were consistently greater in the dorsal region of the central retina, irrespective of developmental stage, suggests that the visual axis for lens accommodation may be forward- and downwardprojecting relative to the snout. This is consistent with the proposed visual axis of other shallow-water larval planktivores (Cobcroft \& Pankhurst 2006).

Although prey size is the dominant factor in larval selection, such other factors as nutritional quality, visibility, evasion speed, and morphological makeup of potential prey are also important (Hunter 1981, Govoni et al. 1986). Auxis rochei larvae are highly active visual predators that have high feeding success from the onset of feeding. However increasing mouth size (jaw length and MW), enhanced vision, digestive development, and improved swimming ability with notochordal flexion lead to changes in the prey type selected, shifting from small to larger, more nutritious prey.

Acknowledgements. The authors are most grateful to the colleagues who worked with them on the MAS surveys. Special mention is due to L. Intxausti for his advice on larval gut content identification and to I. Catalán for his helpful suggestions. This research was funded by the CTM2004-03510-C0201/MAR Project. E.M. acknowledges predoctoral FPI Fellowship support from Spain's Ministry of Education and Science. P.M.P. was supported by a James Cook University Aquaculture and Emerging Species Research Advancement Program Grant. Thanks are also due to J. Corbera for the drawing of the larvae and to R. Sacks who prepared the English version of the manuscript.

\section{LITERATURE CITED}

Breck JE, Gitter MJ (1983) Effect of fish size on the reactive distance of bluegill (Lepomis macrochirus) sunfish. Can J Fish Aquat Sci 40:162-167

Britt LL, Loew E, McFarland WN (2001) Visual pigments in the early life stages of Pacific Northwest marine fishes. J Exp Biol 204:2581-2587

Browman HI, Gordon WC, Evans BI, O'Brien WJ (1990) Correlation between histological and behavioral measures of visual acuity in a zooplanktivorous fish, the white crappie (Pomoxis annularis). Brain Behav Evol 35:85-97

Catalán IA, Alemany F, Morillas A, Morales-Nin B (2007) Diet of larval albacore Thunnus alalunga (Bonnaterre, 1788) off Mallorca Island (NW Mediterranean). Sci Mar 71:347-354

Chesson J (1978) Measuring preference in selective predation. Ecology 59:211-215

Cobcroft JM, Pankhurst PM (2006) Visual field of cultured striped trumpeter Latris lineata (Teleostei) larvae feeding on rotifer prey. Mar Freshw Behav Physiol 39:193-208

Conway DVP, Coombs SH, Lindley JA, Llewellyn CA (1999) Diet of mackerel (Scomber scombrus) larvae at the shelfedge to the south-west of the British Isles and the incidence of piscivory and coprophagy. Vie Milieu 49: $213-220$

González-Quirós R, Anadón R (2001) Diet breadth variability in larval blue whiting as a response to plankton size structure. J Fish Biol 59:1111-1125

Govoni JJ, Ortner PB, Al-Yamani F, Hill LC (1986) Selective feeding of spot, Leiostomus xanthurus, and Atlantic croaker, Micropogonias undulatus, larvae in the northern Gulf of Mexico. Mar Ecol Prog Ser 28:175-183 
Hairston NG Jr, Li KT, Easter SS Jr (1982) Fish vision and the detection of planktonic prey. Science 218:1240-1242

Hay SJ, Evans GT, Gamble JC (1988) Birth, growth and death rates for enclosed populations of calanoid copepods. J Plankton Res 10:431-454

Hubbs C, Blaxter JHS (1986) Development of sense organs and behaviour of teleost larvae with special reference to feeding and predator avoidance. Trans Am Fish Soc 115:98-114

Hunter JR (1981) Feeding, ecology and predation of marine fish larvae. In: Lasker R (ed) Marine fish larvae: morphology, ecology and relation to fisheries. Washington Sea Grant Program, University of Washington Press, Seattle, WA, p 33-77

Kleppel GS, Holliday DV, Pieper RE (1991) Trophic interactions between copepods and microplankton: a question about the role of diatoms. Limnol Oceanogr 36:172-178

Last JM (1980) The food of twenty species of fish larvae in the west-central North Sea. Fish Res 60:1-44

López-Urrutia Á, Acuña JL, Irigoien X, Harris R (2003) Food limitation and growth in temperate epipelagic appendicularians (Tunicata). Mar Ecol Prog Ser 252:143-157

Lythgoe JN, Muntz WRA, Partridge JC, Shand J, Williams DMcB (2004) The ecology of the visual pigments of snappers (Lutjanidae) on the Great Barrier Reef. J Comp Physiol [A] 174:461-467

Margulies D (1993) Assessment of the nutritional condition of larval and early juvenile tuna and Spanish mackerel (Pisces: Scombridae) in the Panama Bight. Mar Biol 115:317-330

Margulies D (1997) Development of the visual system and inferred performance capabilities of larval and early juvenile Scombrids. Mar Freshw Behav Physiol 30:75-98

Menden-Deuer S, Lessard EJ (2000) Carbon to volume relationships for dinoflagellates, diatoms, and other protist plankton. Limnol Oceanogr 45:569-579

Pankhurst PM, Pankhurst NW, Montgomery JC (1993) Comparison of behavioural and morphological measures of visual acuity during ontogeny in a teleost fish, Forsterygion varium, Tripterygiidae (Forster, 1801). Brain Behav Evol 42:178-188

Pearre S Jr (1985) Ratio-based trophic niche breadths of fish, the Sheldon spectrum, and the size-efficiency hypothesis. Mar Ecol Prog Ser 27:299-314

Editorial responsibility: Howard Browman (Associate Editorin-Chief), Storebø, Norway
Poling KR, Fuiman LA (1997) Sensory development and concurrent behavioural changes in Atlantic croaker larvae. J Fish Biol 51:402-421

Putt M, Stoecker DK (1989) An experimentally determined carbon: volume ratio for marine 'oligotrichous' ciliates from estuarine and coastal waters. Limnol Oceanogr 34: 1097-1103

Sabatés A, Recasens L (2001) Seasonal distribution and spawning of small tunas (Auxis rochei and Sarda sarda) in the northwestern Mediterranean. Sci Mar 65: 95-100

Sabatés A, Saiz E (2000) Intra- and interspecific variability in prey size and niche breadth of myctophiform fish larvae. Mar Ecol Prog Ser 201:261-271

Sánchez-Velasco L, Contreras-Arredondo I, Esqueda-Escarcega G (1999) Diet composition of Euthynnus lineatus and Auxis sp. larvae (Pisces: Scombridae) in the Gulf of California. Bull Mar Sci 65:687-698

Sassa C, Kawaguchi K (2004) Larval feeding habits of Diaphus garmani and Myctophum asperum (Pisces: Myctophidae) in the transition region of the western North Pacific. Mar Ecol Prog Ser 278:279-290

Shoji J, Tanaka H (2001) Strong piscivory of Japanese Spanish mackerel larvae from their first feeding. J Fish Biol 59:1682-1685

Tanaka M, Kaji T, Nakamura Y, Takahashi Y (1996) Developmental strategy of scombrid larvae: high growth potential related to food habits and precocious digestive system development. In: Watanabe Y, Yamashita Y, Oozeki Y (eds) Survival strategies in early life stages of marine resources. AA Balkema, Rotterdam, p 125-139

Tudela S, Palomera I, Quílez G (2002) Feeding of anchovy Engraulis encrasicolus larvae in the Northwest Mediterranean. J Mar Biol Assoc UK 82:349-350

Uotani I, Matsuzaki K, Makino Y, Noda K, Inamura O, Horikawa M (1981) Food habits of larvae of tunas and their related species in the area northwest of Australia. Bull Jpn Soc Sci Fish 47:1165-1172

Young JW, Davis TLO (1990) Feeding ecology of larvae of southern bluefin, albacore and skipjack tunas (Pisces: Scombridae) in the eastern Indian Ocean. Mar Ecol Prog Ser 61:17-29

Submitted: April 19, 2007; Accepted: July 29, 2007

Proofs received from author(s): December 12, 2007 